\title{
Los cuentos de guerra y su divergencia: La Lopre, Memorias de una presa política 1975-1979
}

\author{
War stories and Their Divergence: \\ The Lopre, Memoirs of a Political Prisoner 1975-1979
}

\author{
Rossana Nofal \\ CONICET/INVELEC/UNT, \\ Cátedra de Literatura Latinoamericana \\ Facultad de Filosofía y Letras \\ Tucumán, Argentina
}

Artículo de investigación

https://doi.org/10.32719/13900102.2021.49.4

Fecha de recepción: 21 de abril de 2020

Fecha de aceptación: 21 de junio de 2020

Licencia Creative Commons

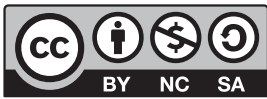




\section{RESUMEN}

"¿Qué sucede cuando hay que intervenir en un texto que fue escrito por alguien letrado aunque su apellido no corresponda a los hacedores de la Patria sino que es el de alguien que se coloca en determinado lugar para narrar una historia reciente?". La pregunta de María Moreno en el epílogo de Memorias de una presa política 1975-1979 interpela la constitución del corpus de las narrativas testimoniales en sus ejes emblemáticos: el familismo patriarcal y la narrativa de la militancia heroica. La recuperación del manuscrito de Graciela La Lopre con los relatos del cautiverio en la cárcel de Villa Devoto, los procesos de edición, los asedios al legado en el que intervienen Cristina Pinal, Mary Dal Dosso, Graciela Dillet, Cristina Raschia y Silvia Gabarain y la organización del relato en el prólogo de Cristina Feijóo desarman los mitos del testimonio letrado. Autoras por delegación, seudónimo y apodo en común enmarcan la pregunta por la posesión del original y un nuevo pacto autobiográfico en el que los personajes del cuento validan los hechos que la literatura narra. La narrativa romántica del intercambio de las cartas de amor con un hombre y la clausura de la vida con suicidio con barbitúricos en un departamento en París alteran los protocolos heroicos y configuran su doblez divergente. Más allá del modelo binario de la construcción de los sentidos entre los hundidos y los salvados, me interesa explorar cómo, el testimonio letrado del cautiverio de La Lopre, en un doble registro de género literario y sexual, inscribe la violencia política desde una mirada de clase. Es el cuento que cuenta el testigo involuntario de la crueldad. No reconoce un mandato militante para cumplir. No sobrevive para contar.

PalabRAS Clave: Argentina, testimonio, género, literario, sexual, militancia, violencia, política, clase.

\section{ABSTRACT}

"What happens when one has to intervene in a text that was written by a literate person although their surname does not necessarily correspond to the Homeland's makers, but rather to someone who places themselves in a particular place to narrate a recent history?". María Moreno's question in the epilogue of Memorias de una presa política 1975-1979 interpellates the constitution of the corpus of testimonial narratives in its emblematic axes: patriarchal familism and the narrative of heroic militancy. The recovery of Graciela La Lopre's manuscript with her accounts of captivity in Villa Devoto prison, the editing processes, the attempts to siege her legacy with the intervention of Cristina Pinal, Mary Dal Dosso, Graciela Dillet, Cristina Raschia and Silvia Gabarain, and the organization of the narrative in Cristina Feijóo's prologue dismantle the myths of the literate testimony. Women authors by proxy, pseudonym and common nickname frame the question regarding the possession of the original and a new autobiographical pact in which the characters of the story validate the facts that literature narrates. The romantic narrative of the exchange of love letters with a man and the termination of life by suicide with barbiturates in an apartment in Paris alter heroic protocols and configure their divergent fold. Beyond the binary model of the construction of the senses among the wrecked and the spared, I am interested in exploring how the literate testimony of La Lopre's captivity, in a double register of literary and sexual genre, registers political violence from a class perspective. It is the story told by the unwitting witness of cruelty. It does not recognize a militant mandate that must be fulfilled. It does not survive to tell.

KEYWORDS: Argentina, testimony, gender, literary, literary, sexual, militancy, violence, politics, class. 
CON MODUlaCiOnes DE vOz divergentes los autores, y por momentos los editores literarios, pueden nombrar a sus fantasmas. Hablar sobre el testimonio como un género escriturario genera una confrontación con la literatura y sus oficios. Entre la verdad y la ficción, la escena del testimonio convoca a un narrador pero también figura un escenario jurídico de prueba para el testigo y sentencia para el victimario. Una temporalidad desplazada hace del testimoniante un relator de su propia experiencia. El tiempo pasado se convierte en un dispositivo de legitimación del discurso propio y, en el mejor de los casos, de reparación subjetiva y social.

Tal como lo señala Susana Kaufman (2018), las cuestiones sobre los efectos subjetivos y sociales de la violencia no cesan, se amplifican con el correr del tiempo y el campo de los derechos humanos las mantiene vigentes. Durante las últimas décadas, otorgar veracidad a los hechos, encontrar un modo de transmitirlos y propiciar el acceso a la justicia otorgaron al testimonio un lugar preponderante en la escena política. Si en el relato, la búsqueda de sentido es lo que caracteriza al narrador, en el testimonio, el lugar de las víctimas de la violencia y su palabra se configuran en experiencia. Es la escucha ajena de otro al yo del testimonio lo que permite entender $\mathrm{y}$ tramitar las consecuencias subjetivas de la violencia.

\section{EL TESTIMONIO COMO GÉNERO}

Desde los dominios borrosos del género testimonial, organicé sus desarrollos teóricos considerándolos como una modulación más dentro de los círculos concéntricos de la ciudad letrada a partir de la incorporación de las militancias revolucionarias tanto en sus lenguajes como en su espacialidad.

Durante los años noventa los viejos militantes y los sobrevivientes contaban sus historias sobre la violencia política de los años setenta en un proceso de reconstrucción ética de una sociedad todavía anclada en la herida del terrorismo de Estado con una política que no reconocía esta experiencia desde lo institucional. Sin embargo, estas historias circularon 
de boca en boca a la vez que ocuparon las mesas de novedades de los sellos editoriales. En cuanto a la tipología discursiva de este nuevo género de memorias, decidí proponer una clasificación de dos corpus textuales: el testimonio letrado y el testimonio canónico tomando como referencia a los sujetos que organizaban una escena oral de transmisión de memorias. Con esta lógica postulé que el testimonio canónico se caracteriza por un sistema desigual de negociación de la palabra escrita ya que el informante es, en general, iletrado, mientras que el protagonista del testimonio letrado pertenece al mismo espacio que su entrevistador, es un intelectual, compilador de recuerdos.

Mientras que el testimonio canónico disputa un espacio en la memoria escrituraria, el testimonio letrado supone un intercambio de experiencias entre los miembros de una misma comunidad, real o imaginada. En Argentina, se trató de testimonios urbanos vinculados a la lógica de los Montoneros, cuya memoria ejemplar se recupera en el libro Recuerdos de la muerte, de Miguel Bonasso (1994). Ser portador del dolor y de la memoria, por haber sido víctima o testigo directo, implica una legitimidad "y una autoridad basados en el monopolio de los significados y contenidos de la verdad y la memoria" (Jelin 2017, 140). Este poder ahoga los mecanismos de transmisión porque no otorga a las generaciones jóvenes el permiso de reinterpretar y hasta incluso interpelar con sentidos propios las experiencias transmitidas.

En los términos de Rama (1984), la lógica del testimonio letrado estuvo siempre en manos de los intelectuales. En mis lecturas sobre el género, sumé la complejidad de la escucha de los relatos de memoria y la necesidad de un lector extraño (Nofal 2009, 2012) para quien la experiencia suponía una diferencia y una distancia de tiempo y espacio. La lejanía en las distintas temporalidades superpuestas permitió la consolidación de narrativas sobre la militancia armada pautadas por una sensación de una “ajenidad" que es a la vez interpretación y transmisión.

"¿Qué sucede cuando hay que intervenir en un texto que fue escrito por alguien letrado aunque su apellido no corresponda a los hacedores de la Patria sino que es el de alguien que se coloca en determinado lugar para narrar una historia reciente?" (Memorias... 325). La pregunta de María Moreno en el epílogo interpela los protocolos de las narrativas testimoniales en sus ejes emblemáticos: la firma de autor, la legitimidad del testimonio, el familismo patriarcal, la narrativa de la militancia heroica 
y la lógica militante del parte de guerra. Se reitera el cuento romantizado sobre de la guerrilla y la divergencia se instala en la performatividad del diario que es a la vez la bitácora de una experiencia carcelaria y una colección de cartas de amor. El epílogo cierra el escenario y su rutina con una arquitectura propia: "Graciela Lo Prete se suicidó ingiriendo barbitúricos el 19 de agosto de 1983".

La recuperación del manuscrito de Graciela Lo Prete con los relatos y las cartas intercambiadas con su compañero durante el cautiverio en la cárcel de Villa Devoto, los procesos de edición, los asedios al legado y la construcción de legitimidad del texto original, son procesos en los que intervienen Cristina Pinal, Mary Dal Dosso, Graciela Dillet, Cristina Raschia y Silvia Gabarain. En el prólogo de Cristina Feijóo cuestiona los mitos del testimonio letrado en relación a la cárcel y a la militancia. "La presencia mayoritaria de presas de las dos grandes organizaciones armadas, PRT y Montoneros, inclinó la balanza con bastante rapidez" y la vida comunitaria quedaría marcada "por una concepción militarista". Entre liderazgos y mandos verticales "se necesitaba mucho coraje intelectual para no sucumbir a esos imperativos a los que muchos de nosotros sucumbimos”. De un lado se alineaban quienes daban prioridad al adoctrinamiento en sus formas militarizadas de la política; del otro lado quienes construían lazos afectivos. "Estas dos maneras de concebir la vida en prisión pugnaban por moldear la identidad colectiva" (14).

\section{PARÍS... ¿ERA UNA FIESTA?}

Analizando tu futuro con una lógica formal, y entonces claro, como ahora, si dejás la Facultad, dejás la posibilidad de tener cosas, amigos, concluís que dentro de tres años, al volver de París (por ejemplo), no tendrás ningún anclaje. (Memorias... 80. Carta de César, 13 de agosto de 1975)

La lectura a contrapelo de las modulaciones de la violencia, las Memorias de una presa politica expone un desplazamiento de la firma de autora singular a un colectivo de editoras que migran la figura de la víctima inmolada y quieta de Graciela/personaje a la agencia de los cuerpos sexuados y en acción de las mujeres en cautiverio. Hay una voluntad de apropiación del manuscrito y su derrotero desde las cartas a las amigas/ 
compañeras del penal con los "espirales de mi propia obsesividad". Hojas de distintos tamaños, escritas con la Lettera 22, a un espacio y en doble faz, se recuperan años después. Autoras por delegación, seudónimo y apodo en común enmarcan la pregunta por la posesión del original y un nuevo pacto autobiográfico en el que los personajes del cuento validan los hechos que la literatura narra.

"Estas memorias se publican tal y como fueron encontradas; las únicas modificaciones hechas al original consisten en la sustitución de nombres propios por seudónimos, con el fin de preservar identidades. Comienzan en julio de 1975 y se extienden hasta enero/febrero de 1976". La firma se convierte en un punto que el protocolo del género, una fuga que se activa cada vez que alguien, en definitiva, se confiesa, testimonia, cuenta un cuento sobre sí. Los "parecidos de familia" son la clave política del género. El testimonio "se toma”. La voz singular inscribe lo social en un interrogatorio al sí mismo y a los otros que lo reciben. Sin embargo, el manuscrito construye un personaje en fuga hacia la melancolía y desdibuja el lugar de autor a la vez que interpela desde la zona gris de la culpa, la vergüenza y la ausencia de una coartada para permanecer en el mundo:

Concebí la idea de llevar un diario de la prisión y emprendí el trabajo; lo hacía a la hora de la siesta, debatiéndome contra el sueño, que era el único momento del día en el que había silencio total; escribía en un cuaderno y luego trasladaba lo escrito dos veces, una en una carta para mi padre, y otra en una carta para Silvia, mi compañera de estudios de Psicología que me apoyaba desde afuera con una fidelidad insospechada. (Memorias... 211)

En el género testimonial, "el valor oro" se mide en términos de una construcción de veracidad alejada de los modos de la ficción. El cuerpo y la voz de la víctima validan la escritura de la sinrazón. El gran organizador de estos protocolos es el intelectual solidario con la causa y unido a ella en términos de una experiencia vital. A la escucha inicial del género, las Memorias de una presa política suma los procesos de edición a la lógica de la escritura de un diario íntimo y su derrotero de cartas duplicadas con destinatarios diferentes. Las historias heroicas de los sobrevivientes borran los fantasmas de la traición y la delación bajo tortura y organizan un imaginario de virtudes políticas en una narrativa sin fisuras (Nofal 2009, 141). 
El epílogo desencantado de María Moreno suma en el manuscrito un quiebre en el triunfalismo autoritario y militarista de la prensa oficial del ERP y de Montoneros. El vínculo que propone para leer las cartas enmascaradas de una novela inconclusa y de firma colectiva es una "sororidad": un sentimiento sin nombre para definir una transición hacia el cuerpo político y el "escándalo" que suscita. "Esa mismidad es la que le permitió a Graciela Lo Prete armar una especie de suelo materno en el 'rincón esquizofrénico', ese que a menudo evoca como un espacio nutricio abrigado y donde la laboriosidad y el tiempo dedicado al tejido o a la comida le devuelven los ademanes de una protección de la que habría carecido en su infancia" (334). La escritura se imagina como una distancia de rescate: "nadie sabrá jamás a partir de qué secreto escribo", incluso más allá de su propia existencia. Ninguna de las mujeres puede hablar de un azar: alguien le entregó a Cristina Pinal el texto de Graciela Lo Prete. “Todavía conservaba mis cuadernos cuando llegó la policía a mi departamento; después desaparecieron, quizás porque eran manuscritos con mi letra" (211). El texto construye su propio enigma de origen en una nueva paradoja de género.

\section{LOS RESTOS: LA DISTANCIA DE RESCATE}

Qué sueño raro tiene la Lopre, duerme con una pierna en el aire. Luego te rescato (...). Luego descubro la forma de hacerme invisible: comiendo la sustancia amarilla. El sueño sigue, ya plagado de aventuras de otro tipo: yo como el hombre invisible, luchando contra los malos. (Memorias... 294)

Analía Gerbaudo (2016) define la acción de la exhumación como "el rescate de géneros o textos rechazados, ocultos, desvalorizados que, como un buque extraño, sufren alguna modificación a partir de esa práctica” $(2016,41)$. Gerbaudo, lectora de Derrida, nunca separa afectos y amistad de su escritura a la vez que suma una sutil diferencia entre "resto" y "ceniza":

El 'resto' no es la sobra de una totalidad preexistente y primera sino aquello que, desde el comienzo exhorta respecto de la imposibilidad de un todo clausurado sin grietas [...] 'Cenizas' es una figura a través de la 
cual Derrida nombra el exterminio. De los soportes y de las materias no queda nada, excepto cenizas. Se pierden los contornos, los colores, los aromas, las texturas, las humedades. (Gerbaudo 2016, 39)

En las cenizas, todo se aniquila; en el resto, se pueden identificar los vestigios del recuerdo. Es difícil "desmentir" los cuentos de la guerra. A partir de los nuevos libretos del Estado de derecho y de la acción eficaz de la justicia y sus reparaciones, la literatura testimonial se permite la configuración de una nueva agenda vinculada a una ficción sobre las memorias en conflicto y una organización de una poética que ya no está obligada a los usos legales del testimonio y el testigo. Sumo a los narradores de Benjamín las lógicas del "cuento" definido por Josefina Ludmer (1977) en términos de relatos anacrónicos y anónimos. Ludmer avanza en la identificación de cuento como partículas de carácter fragmentario que se reiteran como partes de historias mayores. El cuento es entonces, en los términos del género testimonial, un relato sobre el sufrimiento que se reitera con una gestualidad romántica y que compromete la oralidad. La seducción del cuentero que trasmite sus saberes con la inventiva de su experiencia. El heroísmo y su construcción demanda víctimas inmoladas y relatos sin fisuras, el suicido de Graciela Lo Prete desarticula los imaginarios de la victoria siempre y el cielo por asalto.

Los cuentos, en las memorias de una presa politica, no imaginan la sonoridad de una escucha sino la mirada de un lector que asedia interpretaciones y sentidos múltiples. Son trazados narrativos de la propia vida encarnados por una actriz que construye múltiples personajes. "Me di cuenta de todo lo que yo había puesto de mi historia en el personaje de Amelia, porque cuando la vi entretenerse con el tejido me conmovió una rara y gran alegría. Amelia nunca hizo nada acabado, pero se pasó días $y$ dias tejiendo con mi lana, cada vez más enredada y sucia" (102). En las memorias del cautiverio hay una pastoral ordenada: las mujeres son jóvenes, solidarias y entusiastas. Cuidan a sus compañeras del interior, socializan sus pertenencias y por momentos, la cárcel se borra en la musicalidad de una ronda, taconeando La Bamba Guantanemera (35). El cuento no es una fuente histórica; los hechos relatados no prueban una verdad del enunciado con su sola enunciación. Sin embargo, su materialidad explicita las desarticulaciones, los agregados, los silencios, y las contradicciones de 
una mujer desplazada de los mandatos de clase, una desclasada en el borde de un espacio indecible:

Aterricé en la cárcel cuando había abandonado la militancia política. Había sido una cristiana consecuente, después una intelectual culpabilizada y más tarde una militante sin convicción. Moralista entre los intelectuales "puros" y escéptica entre los militantes decididos. Lo único que me faltaba era ser presa política por amistad. Le escribí a César, en mi primera carta, que me parecía digno broche de oro para mi vida signada por la ambigüedad". (Memorias... 77)

Lejos de consolidar una mitología heroica del personaje, la correspondencia con César desnuda sus momentos de ofuscación, capricho, enojo y de obsesiva vigilancia sobre el devenir de un cuento sin regulación. "Me divertía dramatizando el pensamiento del filósofo que estaba estudiando, inventando un personaje que actuaba la vida cotidiana de Buenos Aires representando consecuentemente su teoría” (211). La narrativa romántica del intercambio de las cartas de amor con un hombre y la clausura de la vida en un departamento en París alteran los protocolos heroicos y configuran su doblez divergente. Graciela/Gracilda: "otras veces sos la gata Flora del cuento que me mandaste, que por no querer ser extranjera en algún lugar terminó siéndolos en todos, y aquí tu color es el azul” (Memorias... 292).

Más allá del modelo binario de la construcción de los sentidos entre los hundidos y los salvados, el testimonio letrado del cautiverio de La Lopre, en un doble registro de género literario y sexual, inscribe la violencia política desde una mirada de clase. Es el cuento que cuenta el testigo involuntario de la crueldad. No reconoce un mandato militante para cumplir. No sobrevive para contar. "yo había abandonado toda inserción social por la militancia y mi militancia tenía el signo de mi compañero [...] cuando dejé la organización, estaba en el aire" (37).

En Memorias de una presa politica, se pasa dos veces por la misma experiencia: entrar a la cárcel. En la primera parte, Graciela Lo Prete cuenta la llegada a Devoto en julio de 1975. En el inicio de la segunda parte se cuenta el traslado a otro pabellón mucho más poblado (lo que coincide con el cambio abrupto del tipo de experiencia carcelaria, a tal punto que es como "volver a entrar". La primera entrada se reconstruye desde un colectivo "en total habría unas veinticinco camas / me sorprendió la amplitud y 
la limpieza que allí reinaban" [...] nunca hubiera imaginado así el pabellón de una cárcel" / mi sorpresa fue enorme: la de encontrar una continuidad entre mi vida y esa situación anormal en la que estaba" (21). Lo que había sido desfile entre las mujeres, con vestuario y mascarada, lascivia patética de "tenues" nocturnas, se convierte en desfile ante los represores a contraluz "sabiéndonos miradas, algunas de nosotras impostaban la fiereza, otras en cambio la debilidad, o la ternura" (157).

Esta operación de lectura implica pensar las divergencias que se instalan en la escritura a partir de la inscripción de los modos en que los cuentos atraviesan no solo una lógica territorial marcada por los itinerarios de las guerrillas, sino también por la inscripción de las marcas identitarias, de sus diferentes lenguajes y de sus restos narrados en las experiencias de cautiverio entre Tucumán y Villa Devoto. El cuento más extraño es el de la guerra de guerrillas en la contraposición de dos voces: Dora enuncia la guerra y los discursos triunfalistas: "el ERP resistía con éxito las pinzas del ejército" (56); Blanca, “desamparada” desnudaba la mentira: "Tucumán no es una zona liberada $[\ldots]$ los están matando a todos $[\ldots]$ ". Para qué tienen que mentir (59). Un cuento romantizado de la violencia que se desconstruye en el testimonio junto con las máscaras heroicas de sus narradoras.

El testimonio, género y narrativa de la urgencia, es siempre contingente, porque la víctima corre el riesgo de morir antes de hablar o de encontrar los huesos de los suyos. El texto figurado de Graciela Lo Prete figura un manuscrito y su derrotero entre la requisa, la cárcel, el exilio y el suicidio. Resto precario del fracaso de los proyectos revolucionarios y transmisión generacional de la memoria. El testimonio letrado inscribe, en un doble registro de sentido, el testigo y su personaje narrado. Es el cuento que cuenta un hallazgo involuntario. La Lopre recuperada por colectivo más próximo no tiene un mandato militante. No sobrevive para contar. La palabra desnuda se edita para que algo aparezca, para que algo se encuentre como marca de los cuerpos ausentes en las ciudades de la memoria: Tucumán, Buenos Aires y París. Un corredor de sueños que se clausura en la carta inconclusa "para protegerte del frío o por”, o porque no puede contar el final de su protagonista. 
KİPUS 49, enero-junio 2021

\section{Lista de referencias}

Jelin, E. 2017. La lucha por el pasado. Cómo construimos la memoria social. Buenos Aires: Siglo XXI.

Kaufman, S. 2018. "Perspectivas subjetivas sobre el testimonio. Experiencias límites, lenguajes y formas de representación”. En Avatares del testimonio en el Cono Sur. Cartografías. Voces. Experiencias, coordinado por T. Basile y M. Chiani. La Plata: EDULP (en prensa).

La Lopre, Graciela. 2006. Memorias de una presa política 1975-1979. Buenos Aires: Norma.

Nofal, R. 2009. "Literatura y testimonio". En La investigación literaria. Problemas iniciales de una práctica, dirigido por M. Dalmaroni. Santa Fe: Secretaría de Extensión, Universidad Nacional del Litoral.

—. 2012. "Cuando el testimonio cuenta una guerra". El hilo de la fábula, 12: 91101 .

-.2015. "Configuraciones metafóricas en la narrativa argentina sobre memorias de dictadura". Kamchatka, 6: 835-51.

Rama, A. 1984. La ciudad letrada. Hanover: Ediciones del Norte. 